\title{
ERRATUM
}

\section{Erratum to: Venoarterial extracorporeal membrane oxygenation for cardiac arrest/ cardiogenic shock}

Anders Aneman ${ }^{1 *}$ and Peter Macdonald ${ }^{2}$

๑ 2016 Springer-Verlag Berlin Heidelberg and ESICM

\section{Erratum to: Intensive Care Med}

\section{DOI 10.1007/s00134-016-4624-9}

Owing to an error in the manuscript supplied for publication, the title of this editorial was incorrect. The correct title is "Venoarterial extracorporeal membrane oxygenation for cardiac arrest/cardiogenic shock".

\section{Author details}

${ }^{1}$ Intensive Care Unit, South Western Sydney Local Health District, Liverpool Hospital, University of New South Wales, Ingham Institute for Applied Medical Research, Sydney, NSW, Australia. ${ }^{2}$ Heart and Lung Transplant Unit, St Vincent's Hospital, University of New South Wales, Victor Chang Cardiac Research Institute, Sydney, NSW, Australia.

Published online: 24 November 2016

The online version of the original article can be found under doi:10.1007/s00134-016-4624-9.

*Correspondence: anders.aneman@swsahs.nsw.gov.au ${ }^{1}$ Intensive Care Unit, South Western Sydney Local Health District, Liverpool Hospital, University of New South Wales, Ingham Institute for Applied Medical Research, Sydney, NSW, Australia

Full author information is available at the end of the article

\section{會 Springer}

